\title{
José Miguel Silva e a imortalidade de Ulisses
}

\author{
Carolina Donega Bernardes ${ }^{1}$
}

\begin{abstract}
RESUMO: Largamente retomado pela tradição literária, o tema da viagem de Ulisses confirma em algumas obras o ideal do herói nostálgico que se dirige ao lar em cumprimento de seu nóstos; enquanto que em outras obras reafirma-se o ímpeto do eterno navegador de mares. Seguindo essa tendência na contemporaneidade, José Miguel Silva encontra na Odisséia homérica a matéria e a forma para compor Ulisses já não mora aqui (2002).
\end{abstract}

ABSTRACT: Always invoked by the literary tradition, the travel of Ulysses confirms, in some works, the ideal of the nostalgic hero going back home in order to accomplish his nóstos, while in other works is reaffirmed the impetus of the eternal sailor. Contemporaneously, José Miguel Silva also finds in the Homeric Odyssey the material and the form to write Ulisses já não mora aqui.

PALAVRAS-CHAVE: José Miguel Silva; Ulisses; Pós-modernidade; Herói KEYWORDS: José Miguel Silva; Ulysses; Post-modernity; Hero

O tema da viagem de Odisseu foi largamente retomado pela tradição literária após a Odisséia de Homero, seja para confirmar o ideal do herói nostálgico, que anseia o retorno à pátria, seja para reafirmar o ímpeto do eterno navegador de mares, tendo sido desenvolvido por autores como Dante, Tennyson, Shakespeare, Giovanni Pascoli, Gabriele d'Annunzio, James Joyce, Haroldo de Campos e Nikos Kazantzakis, entre outros. Apesar de muitos autores se inspirarem no retorno de Odisseu como meta da navegação, é forte a tradição que escolhe representar o herói como insatisfeito com a chegada ao lar almejado e desejoso de continuar a viagem. Odisseu é uma figura que não se esgota e não se limita aos poemas homéricos,

1 Doutoranda em Teoria da Literatura - UNESP (São José do Rio Preto). Pesquisa: "Nikos Kazantzakis e o itinerário heróico da Odisséia moderna". Bolsista FAPESP. Contato: biabeca@gmail.com 
sendo definido, genericamente, pela crítica contemporânea como um "discurso" da civilização ocidental.

Para Piero Boitani, em A Sombra de Ulisses (2005), Ulisses é um signo aberto ao futuro e localizado no limiar entre o antigo e o moderno. Deste modo, cada cultura o interpreta conforme seu próprio sistema de signos, atribuindo ao herói ora seu significado mítico, ora os ideais e questões de seu tempo. "Ele é um personagem mítico e literário que intérpretes, poetas e historiadores lêem retórica e profeticamente como typos: sombra que se alonga, transformando-se, na imaginação ocidental.” (BOITANI, 2005) Explica-se, portanto, a retomada constante da figura de Ulisses ao longo da história, recebendo significados distintos nas diversas épocas e culturas pelas quais foi representado.

Essa abertura para o futuro constitutiva do herói Ulisses deve-se principalmente a um elemento da própria Odisséia de Homero: a previsão de Tirésias no canto XI. Revelando a morte do herói na velhice de modo ambíguo (a expressão grega ex halos pode significar "fora do mar" ou "vinda do mar"), a intervenção de Tirésias abre um vazio de mistério que será preenchido em épocas posteriores. A profecia do adivinho prolonga o futuro do poema e da própria Odisséia, mesmo após o seu término.

Segundo a previsão do conhecido adivinho, após o seu retorno a Ítaca, Odisseu deveria enfrentar "uma enorme prova, longa e dificil", embarcando para uma última viagem, e levando consigo, nos ombros, um remo; deveria, em seguida, prosseguir seu trajeto até chegar a um país cujos habitantes não conhecem nem a comida temperada com sal, nem o mar, nem os remos, "que são para as naus as asas". Então Odisseu deveria praticar sacrifícios apropriados para aplacar definitivamente a ira de Poseidon; só então a morte chegaria ex halos "tão serenamente que o encontrará consumido por esplendorosa velhice".

A profecia, no entanto, não se concretiza em Homero, permitindo, assim, que os leitores da obra completem como lhes aprouver as várias possibilidades assinaladas pelo vate sentenciador também do destino do 
rei Édipo. Por essa previsão, Odisseu torna-se uma figura de longa duração, aberta às diversas interpretações, que intentam completar o anúncio de Tirésias. Assim, além de revelar a morte do herói pela expressão ambígua, o adivinho abre mais uma possibilidade para o futuro: sua viagem não terminaria com a chegada a Ítaca, como ocorre em Homero, mas se prolongaria para além do nóstos. Desse modo, Odisseu torna-se o viajante por excelência, ininterruptamente.

A partir desse momento, e cada vez que empreende aquela viagem, ele é signo. Cada cultura está livre para interpretá-lo como tal no âmbito de seu próprio sistema de signos, atribuindo-lhe uma dupla valência, ora baseada nas características míticas do personagem, ora nos ideais, nas questões, nos horizontes filosóficos, éticos e políticos daquela civilização. Histórica e múltipla torna-se sua representação, recebendo significados diversos em cada cultura.

Nosso intuito neste artigo, porém, não deverá se encerrar na representação da última viagem de Odisseu dada por diversos autores, principalmente na modernidade, mas pretendemos abarcar outra concretização do mito realizada na pós-modernidade pelo poeta português José Miguel Silva.

Fernando Pessoa escreve Mensagem, na qual dedica um poema a Ulisses; José Miguel Silva escreve Ulisses já não mora aqui. Ambas as obras sinalizam a importância do mito de Ulisses nas letras portuguesas, que, de um modo singular e particular, se fundamenta por outra representação do herói, diferentemente das tradições que se fixaram no decorrer da história, interpretando (e reatualizando) Ulisses como nostálgico navegador ou como insaciável de conhecimento. Na literatura portuguesa, Ulisses é o fundador, o construtor de cidades e, desse modo, uma figura nacionalista, que faz parte da história de Portugal.

Canta-me, ó Musa, o homem fértil em expedientes, que muito sofreu,

Que destruiu a cidadela sagrada de Tróia, 
Que viu as cidades de muitos homens e conheceu o seu espírito, Que padeceu, sobre as ondas, muitas dores no seu coração. ${ }^{2}$

A invocação à Musa em Homero desnuda o espírito de Odisseu e reflete a visão portuguesa do herói: não só a engenhosidade múltipla revela seu caráter, mas o expansionismo, que o leva a estranhas terras e o torna fundador mítico de múltiplas cidades (o que o liga, invariavelmente, à tradição do "insaciável de conhecimento", ainda que não se estenda à sua última viagem profetizada por Tirésias), como por exemplo, e particularmente, a cidade de Lisboa, chamada de Olisipone ou Ulixibona, uma derivação do nome do herói. Constrói muralhas em Lisboa e um templo a Atena, em gratidão à sua proteção nos feitos de Tróia e no retorno à pátria. Se, porém, Odisseu é conhecido como construtor, o oposto é igualmente verdadeiro, como canta o poema de Homero. Odisseu edifica muralhas em terras estrangeiras, mas destrói as de Tróia por sua astúcia. Essa dupla caracterização do herói pode ser reconhecida já em Camões:

Vês outro que do Tejo a terra pisa,

Depois de ter tão longo o mar arado, Onde muros perpétuos edifica, E templo a Palas, que em memória fica. Ulisses é o que fez a santa casa À Deusa, que lhe dá língua facunda, Que se lá na Ásia Tróia insigne abrasa, Cá na Europa Lisboa ingente funda. ${ }^{3}$

Tanto a epopéia de Camões quanto o poema Mensagem de Pessoa (PEREIRA, 1997) se dirigem a uma construção mítica e nacionalista de Portugal, poetas esses representativos da alma e das letras portuguesas. E se Ulisses faz parte dessa formação de Portugal, como a figura de mais longa duração do Ocidente, permanece na atualidade como matéria do lirismo de José Miguel Silva.

Ulisses já não mora aqui (2002) parte, evidentemente, das múltiplas tradições do mito ulisseano, estabelecendo desde o título uma

2 Homero. Odisséia, I, 1-4.

${ }^{3}$ Lusiadas, VIII.4.5-5.4 
interlocução com as diversas outras representações realizadas na história literária. A obra, constituída por uma reunião de poemas, configura a antiga trajetória narrativa, pela divisão em sessões que recebem subtítulos referentes às famosas peripécias do herói em sua odisséia. Desse modo, os poemas devem ser lidos e entendidos em conjunto, alinhavados em seqüência e obedecendo a sucessão dos episódios que se interpõem, características essenciais do gênero narrativo.

A presença do lirismo associado a elementos narrativos em Ulisses já não mora aqui possivelmente nos remete ao gênero épico, o que nos levaria a pensar em uma reafirmação do nacionalismo. Porém, parece-nos ser possivel realizar uma análise mais produtiva do que filiar o autor ao ufanismo e à tentativa de re-fundação de seu país. O resgate de uma tradição por demais arraigada no imaginário ocidental como a de Ulisses e sua odisséia, ligada intimamente com questões particulares de um país, reflete um impulso de reimaginar os dados do passado, a herança cultural universal (e local), e reoperá-los na instância vital e problemática do presente. O presente seria, desse modo, reavaliado a partir do olhar dirigido ao passado, como impulso vital para a renovação e a análise crítica da situação atual, como se a distância temporal, ao contrário de separar as épocas pela diferença, aproximasse-as pela repetição e prolongamento das mesmas questões. Odisseu permanece sempre vivo nas civilizações e serve de protótipo do reconhecimento de si mesmo e do mundo exatamente por sua caracterização múltipla e por seu vasto conhecimento, encerrando em si todas as potencialidades humanas.

O itinerário traçado por José Miguel Silva, apesar de se referir aos episódios da Odisséia, não concorda com o de Homero, pois lhe dá outra configuração. O poeta português abre sua obra com a sessão intitulada "Ciclopes", o que nos remete imediatamente às questões sociais e culturais. O mundo civilizado e real, aos olhos de Homero, pertence aos homens que cultivam a terra e conhecem o trigo para fazer o pão. A cultura do trigo é um critério absoluto para essa distinção 
entre os homens civilizados e os selvagens (VIDAL-NAQUET, 2002). E Polifemo, o conhecido Ciclope, faz parte de um povo que não conhece nem a agricultura nem a vida em sociedade.

Porém, a sessão não se avulta com o título "Polifemo", o que seria uma individualização dentre o seu povo, mas ao contrário, marcando o sentido do coletivo, do social, encontramos o título sugestivo "Ciclopes". Ulisses já não mora aqui começa, portanto, com o exercício de pensar a ontologia na vida social por meio de elementos negativos, que afloram no esquecimento do existencial. A vida em sociedade seria, pois, responsável pelo apagamento do sujeito e impulsionadora da formatação (negativa) do indivíduo.

A beleza, "ditirâmbica ilusão" (Salão de Beleza - $1^{\mathrm{a}}$. Impressão), é almejada e perseguida com insistência, mas tudo o que resta a "quem vive o abandono das cidades" é a morte e a sua "estúpida carreta fúnebre" (Salão de Beleza - $2^{\mathrm{a}}$. Impressão). $\mathrm{E}$ os cidadãos, pejorativamente urbanos, irrompem em salões comerciais, em feiras de livros, escondendo a destruição que rodeia a todos. Na há saída, todos rumam para o mesmo fim, para o mergulho na morte. "Neste cerco, viver é uma questão/ de prorrogar o desalento, de iludir/ o infortúnio (...)"; assim, o poeta inaugura a obra com a sessão da destruição, que é o "centro do inferno" para o qual os homens se dirigem, embora enganem a consciência com a mentira e a hipnose.

O engano perdura na sessão "Entre Cila e Carídbis" (Caríbdis em Homero). Surgem as muitas tentativas de esperança as quais o homem pode se agarrar para camuflar a morte vindoura: a crença em Deus (Poema com apólogo moral); o amor, ligado ao seu revés (A minha musa) - a incompatibilidade, o desencontro, a impossibilidade de amar e a conseqüente solidão -; a atividade de poeta e a sua inocuidade (Numa biblioteca); a ação correta vã (Queixas de um utente). E toda a esperança, bem assinalado fica em todos os poemas, vem marcada pela duplicidade da não-esperança, do desalento, da inação diante da fatalidade de não salvar o mundo ou ser feliz. Resta seguir dormindo a civilização, sem tentativas de evasão ou de recordação de tempos 
possiveis, e navegar cegamente, ao acaso, tateando no imenso mar a idéia do encontro de uma porta flutuando - o apoio contra a submersão, a "abertura" a outro plano de consciência. No entanto, tal possibilidade de transcendência simbolizada pela porta não se concretiza: o poeta bem encerra que a noite, a escuridão da cegueira, "nada ensina/ e tudo é sem remédio", os cegos, pois, que tropeçam uns nos outros, não encontram a porta.

Mas ao chegar à "Pátria dos Lotófagos [e] à Ilha de Circe", descobre-se outra possibilidade para encarar a destruição dos ciclopes (que nada têm de civilizados): o esquecimento, representado tradicionalmente por ambos os episódios protagonizados por Ulisses - a folha de lótus que produz o esquecimento e a ação da deusa Circe em estimular as emoções instintivas no herói para afastá-lo de sua pátria. Estamos, portanto, diante de um possivel remédio, contrariamente ao que afirma o eu - lírico no poema "Trevas" da sessão anterior.

Mais uma vez, porém, o engano está presente, pois o esquecimento só se efetiva com o auxilio de artifícios: a festa como produtora de ilusões, concentrando em um mesmo recinto pessoas que utilizam a máscara da alegria e da descontração e que procuram alcançar certo êxtase efêmero para o esquecimento do antes e do depois (No pronto a vestir); o vinho, principal entorpecente e estimulante das potencialidades adormecidas, utilizado inclusive como ritual dionisíaco para a divinização do humano, em contraste com a fraqueza do homem e insipidez da vida na sobriedade (Colheita de 98); as mudanças, como esquecimento do passado, do que não deu certo, da rotina, das gastas e previsiveis ilusões (Por exemplo, mudar de casa); a própria arte da palavra, com sua potencialidade anestésica de regular o "curso da tristeza" (Nocturno); a livraria em Segóvia, que afasta da multidão, que absorve pela leitura e afugenta a passagem do tempo, momento transubstancial do efêmero para o atemporal (Passagem); o esquecimento de todo o torpor, de tudo que inebria, como a consumição do amor, ou melhor, da perda desse amor (Fala Circe); a liberdade de 
afastar-se da não-memória, do apagamento de si (Abandonando a Ilha de Circe).

Mas se o eu-lírico vence mais uma etapa de seu percurso, o alento do esquecimento, alcança novamente o desalento, que se esconde atrás de uma pedra. Como Ulisses, o eu-lírico chega ao Hades, mas como o viajante que carrega "um bilhete sem retorno", e ali encontra diversas almas mortas, que lhe vêm contar sua história, reconhecidamente como o herói de Homero: Elpenor, D. Feia, o Guarda-freio, o Cauteleiro. Mas o Hades não se localiza somente em um mundo subterrâneo, distante da Terra, o eu-lírico o encontra na própria vida, onde já não reconhece nenhum herói, pois estão todos mortos. Não há mais combatentes desde a queda de Tróia, não há deuses direcionando as ações e toda a poesia se tornou improficua. Desse modo, o poeta estabelece uma diferenciação entre a época áurea da Grécia Clássica e a esterilidade e abandono da época atual, contemporânea ao poeta.

Transparente é a consciência do abandono pelos deuses e do caráter ínfimo da vida cotidiana em Ulisses já não mora aqui, sem exigências que mereçam os feitos grandiosos do homem moderno, levando-o ao anonimato e à consumição na coletividade. A angústia da vida moderna encontra-se nessa perda do nome e da fama e, em contrapartida, na aporia da individualização característica dessa época; diferente da coletividade, o indivíduo moderno não se distingue dos demais em suas ações, são todas elas comuns, genéricas, opacas. ${ }^{4}$

Contrastar o homem destituído de habilidades do presente com o herói multiardiloso que inaugura a literatura ocidental pode ter sido um modo de não só problematizar a crise que permeou as primeiras décadas do século XX (o que não deixa de se confirmar nas décadas posteriores), desencadeada pelo fim da Primeira Guerra Mundial, revelando a fragilidade dos ideais humanistas e a consciência do

${ }^{4} \mathrm{O}$ tema foi antes desenvolvido por James Joyce em Ulysses. Leopold Bloom é um homem comum, sem qualquer traço que o eleve em sua categoria, porém um dia seu tem a enormidade de uma epopéia e os eventos ocorridos têm o revestimento de grandes acontecimentos, ainda que superficialmente sejam parte da vida cotidiana e comum de todos os homens. 
declínio histórico das culturas, mas de também estabelecer o conflito de forças irreconciliáveis e engendrar um espaço de embate entre elas.

Os ecos da desolação que atingiu os meios culturais se estendem ainda à época "pós-utópica", pois se observa a necessidade de debate com o cânone e com o passado, mesmo que seja para reoperá-lo no presente, de releitura do homem urbano debilitado e, consequentemente, de análise crítica e irônica dessa orfandade que se abate sobre a individualidade moderna. A literatura mais recente voltase ao modernismo como herdeira natural, mas despende-lhe um olhar, muitas vezes, derrisório em relação à problemática das forças díspares que se entrechocam no espaço do texto literário, como a zombar da atmosfera de crise que pairava no ar e se transubstanciava em escrita fragmentada e múltipla, em sua ânsia por apanhar o todo e o nada que caracterizava a vida e o mundo.

Em José Miguel Silva, no entanto, essa mesma problemática é analisada com o olhar pessimista, daquele que busca a ação de alguém emblemático e nada encontra, ao contrário caminha pela mesma terra estéril de T.S. Eliot. Deuses e heróis estão todos mortos e não podem ser encontrados nem mesmo no Hades, deles nada mais se sabe pois "o canto dos aedos decaiu em jornalismo"; assim, se não há heróis, como o próprio título da obra reitera, tampouco a literatura pode ser a salvação. Esta sessão de Ulisses já não mora aqui encerra o completo niilismo, em sua forma mais radical, pois não há via positiva de criação, como propõe Nietzsche. O enfrentamento da morte e do apagamento é realizado por meio de ameaças desesperadas ("se torno a ver-te a menos de quinze passos/ dos meus - eu juro que te mato"), sem qualquer lógica, que denotam a impotência humana e total submissão.

Enfim, a viagem termina e chegamos à Ítaca, onde Penélope espera. O porto-seguro do eu-lírico está circunscrito ao ambiente caseiro, ao encontro do amor e às pequenas coisas vividas no lar. Fica clara a concordância do poeta com o fim de Ulisses dado por Homero, reintegrando-o ao paraíso perdido, à nostálgica pátria, onde deixara os seus e a felicidade almejada. Protegido nesta Ítaca, o eu-lírico distancia- 
se de toda a descrença e destruição encontradas em seu peregrinar, no mundo da convivência coletiva.

A reviravolta de cosmovisão fica marcada por seu retorno (o nóstos), pelo alcance do télos. Restabelecido ao seu lugar utópico, de origem, o espaço da pátria e do coração, o eu-lírico lança em contraposição ao niilismo anterior: "Qualquer homem é um herói/ Pelo simples facto de morrer/ E os heróis são os nossos mestres”. O valor da heroicidade é recuperado e transferido para os antepassados, sinalizando uma reconciliação com a morte e a reavaliação da ação heróica: morrer é mais difícil que viver.

Em Ulisses já não mora aqui, o eu-lírico se decepciona com a recompensa ao chegar em Ítaca, a felicidade é, em realidade, inferior ao que fora imaginado; no entanto, é a felicidade, é a consolação. A idade chega para Ulisses que realiza sua escolha: o que importa não é morrer ousando longe de casa, mas se contentar com a mínima alegria da vida breve. No poeta português, o Ulisses transformado em homem comum (o everyman de Joyce) troca "a vida pelo pão caseiro", pois "o resto é ruído, inferno de sobra".

Assim, a modo de arremate, cada vez que se revisita o tema de Ulisses, novos conceitos e configurações se acrescentam à sua figura, pois os valores das respectivas épocas e culturas de sua representação são natural e forçosamente inseridos no contexto primitivo, como avaliação e recriação perenes: aventura incessante do conhecimento e da criação.

\section{Referências Bibliográficas}

BOITANI, Piero. A Sombra de Ulisses. São Paulo: Ed. Perspectiva, 2005. HOMERO. Odisséia. Tradução: Carlos Alberto Nunes. Rio de Janeiro: Ediouro, 1967.

PEREIRA, Maria Helena da Rocha. "Ulysses e a Mensagem". In: PESSOA, Fernando.Mensagem. Poemas esotéricos. Edição crítica: José 
Augusto SEABRA (coord).Madrid, Paris, México, Buenos Aires, São Paulo, Lima, Guatemala, San José de Costa Rica, Santiago de Chile: ALLCA XX, 1997, p. 303-313.

SILVA, José Miguel. Ulisses já não mora aqui. Lisboa: \& etc, 2002. STANFORD, W.B. The Ulysses Theme. Ann Arbor, 1968. 